\title{
Avaliação da Qualidade de Vida dos Colaboradores com Foco em Humanização
}

\author{
Martins, Maria Cleusa; Reis, Edilma Elvia dos; Honório, Priscila Carla Moura; Marin, \\ Márcia Lúcia de Mário; Pinto, Vanusa Barbosa; Cruz, Lucila Pedroso da \\ Hospital das Clínicas da Faculdade de Medicina da Universidade de São Paulo - \\ maria.cleusa@hc.fm.usp.br
}

\begin{abstract}
Introdução: a humanização na saúde é uma política que tem como objetivo tornar a assistência mais humana. o trabalhador, precisa ser reconhecido como fundamental, merecedor de atenção, e ser integrado em ações que visem a melhoria da qualidade de vida no trabalho, nos aspectos ligados ao bem estar geral das pessoas. Os profissionais de saúde necessitam de condições básicas, materiais e humanas para estabelecer contato efetivo com os usuários. Desta forma é importante que haja o momento em que o profissional receba o olhar atencioso de seus líderes para que sejam integrados a ações que visem melhoria da qualidade de vida no trabalho. um programa de Qualidade de Vida no Trabalho deve fazer com que os trabalhadores sintam-se bem em trabalhar na empresa e motivados a fazer do ambiente de trabalho um lugar agradável, produtivo e humano. Objetivo: Avaliar a qualidade de vida da força de trabalho da Farmácia Hospitalar de um hospital geral, universitário e público. Método: para coleta de dados utilizou-se o Questionário de Qualidade de Vida SF-36 (The Medical Outcomes Study 36- item Short Form Health Survey), que avalia capacidade funcional, limitação por aspectos físicos, dor, estado geral de saúde, vitalidade, aspectos sociais, limitação por aspectos emocionais e saúde mental, complementado com oito indicadores de qualidade de vida do modelo de Walton: remuneração, benefícios extras, salubridade, equipamentos de proteção individual e coletivo, orgulho do trabalho, relacionamento interpessoal, importância das tarefas executadas e crescimento profissional. Resultados: dos 157 funcionários da Farmácia Hospitalar, 123 (78\%) responderam a pesquisa, 09 (6\%) recusaram a responder e 25 (16\%) estavam ausentes no período do estudo. Quanto ao perfil demográfico, houve predomínio do gênero feminino $(66,39 \%)$, da faixa etária entre 31 e 50 anos (31,5\%), do tempo de serviço na instituição entre $01-10$ anos $(55,73 \%)$, carga horária de 40 horas semanais $(68,03 \%)$ e escolaridade de nível superior (46,71\%). Os pontos críticos encontrados nas respostas ao questionário SF-36 foram vitalidade, dor, estado geral de saúde. no modelo de Walton, os maiores índices de insatisfação foram atribuídos à remuneração, benefícios extras e salubridade. Discussão: Os resultados Globais obtidos evidenciaram boa qualidade de vida no trabalho da equipe funcional da Farmácia Hospitalar, mas também apontaram necessidade de melhoria dos programas de qualidade de vida existentes na instituição, com abordagens em técnicas para lidar com o estresse e autoconhecimento. Conclusão: Esses resultados incentivaram os programas de treinamento técnico, de missão, visão e valores da Farmácia e discussão sobre as principais dificuldades da rotina diária e corroboraram a importância de atividades de integração entre os colaboradores como festa junina, de natal, aniversariantes do mês e a necessidade da avaliação periódica da qualidade de vida da equipe de colaboradores.
\end{abstract}

Martins, Maria Cleusa; Reis, Edilma Elvia dos; Honório, Priscila Carla Moura; Marin, Márcia Lúcia de Mário; Pinto, Vanusa Barbosa; Cruz, Lucila Pedroso da. Avaliação da Qualidade de Vida dos Colaboradores com Foco em Humanização. In: Anais do Congresso Internacional de Humanidades \& Humanização em Saúde [= Blucher Medical Proceedings, num.2, vol.1]. São Paulo: Editora Blucher, 2014. ISSN 2357-7282

DOI 10.5151/medpro-cihhs-10375 